\title{
KAJIAN PEMBERDAYAAN KAKAO RAKYAT MENJADI MASYARAKAT MANDIRI MELALUI AGROINDUSTRI
}

\section{STUDY OF EMPOWERING COCOA PEOPLE BECOME INDEPENDENT COMMUNITY THROUGH AGROINDUSTRY}

\author{
Lucyana Trimo $^{1 *}$, Syarif Hidayat ${ }^{2}$, Lies Sulistyowati ${ }^{1}$ \\ ${ }^{1}$ Departement of Social and Agricultural Economic of Agricultural Faculty of Universitas \\ Padjadjaran \\ ${ }^{2}$ Departement of Plant Pest and Diseases of Agricultural Faculty of Universitas Padjadjaran \\ *E-mail: lucy.trimo@gmail.com; lucyana.trimo@unpad.ac.id \\ (Diterima 27-10-2019; Disetujui 29-11-2019)
}

\begin{abstract}
ABSTRAK
Usaha pemerintah untuk meningkatkan daya saing kakao Indonesia di dunia internasional telah dilakukan dengan mencanangkan Gerakan Peningkatan Produksi dan Mutu Kakao Nasional (GERNAS). Agar gerakan GERNAS terlaksana, maka pembangunan wilayah perlu dilakukan secara komprehensif, terutama pada sentra-sentra komoditas unggulan, seperti komoditas kakao di Luwu Raya pada Provinsi Sulawesi Selatan, yang masih cenderung menghasilkan biji kakao (bukan dalam bentuk olahan), oleh karena itu agar kakao rakyat lebih mandiri maka pemberdayaan harus diarahkan ke agroindustri, dan itu menjadi hal yang urgen. Untuk memberdayakan kakao rakyat menjadi masyarakat mandiri berbasis agroindustri kakao, harus didukung oleh komoditas kakao nya sendiri mulai dari on-farm sampai off-farm yang saling terkait satu sama lain, dan bersifat terpadu dan berkelanjutan. Teknik penelitian menggunakan pendekatan survey. Tempat penelitian merupakan sentra kakao di Indonesia, yaitu Luwu Raya di Provinsi Sulawesi Selatan. Teknik pengumpulan data: studi kepustakaan dan wawancara dengan pihak terkait, yaitu pejabat pada instansi pemerintah, koperasi, pabrikan, asosiasi petani kakao, kelompok tani kakao dan agroindustri kakao rakyat yang dipilih secara purposive. Data sekunder dikumpulkan dari: dokumen atau transkip di instansi terkait, dan jurnal. Data dan informasi yang diperoleh selanjutnya dianalisis secara deskriptif korelatif. Berdasarkan hasil penelitian, pemberdayaan kakao rakyat agar dapat menjadi masyarakat mandiri, dapat dilakukan melalui agroindustri menjadi suatu keniscayaan. Agar menjadi masyarakat mandiri maka yang harus dilakukan adalah: (a) melakukan alih teknologi berdasarkan potensi lokal, (b) fasilitasi pemerintah dalam penyediaan dana talangan dan mesin pengolah, dan (c) dukungan dalam regulasi yang berpihak kepada petani.
\end{abstract}

Kata kunci: pemberdayaan, kakao rakyat, masyarakat mandiri, alih teknologi industry, integrasi

\begin{abstract}
Government efforts to improve the competitiveness of Indonesian cocoa in the international world have been done by launching the National Cocoa Production Improvement and Quality Movement (GERNAS). In order for the GERNAS movement to take place, the development of the region needs to be done comprehensively, especially in the leading commodity centers, such as cocoa commodity in Luwu Raya in South Sulawesi Province, which still tends to produce cocoa beans (not in processed form) The people are more independent then empowerment should be directed to the agroindustry, and it becomes an urgent thing. To empower people's cocoa into an independent community based on cocoa agro-industry, it must be supported by its own cocoa commodities ranging from on-farm to off-farm that are interconnected with each other, and are integrative and sustainable. The research technique is descriptive survey approach. The selected research site is Luwu Raya in South Sulawesi Province. Data collection techniques were conducted by: library study and interview with related parties, ie officials at government institutions, cooperatives, manufacturers, associations of cocoa farmers, and farmers groups selected purposively. Secondary
\end{abstract}


data mining is done by collecting: documents or transcripts in related institutions, and journals. Data and information obtained then analyzed by descriptive correlative. Based on the results of the research, empowering people's cocoa into an independent community through agro-industry becomes a necessity. In order to become an independent community, what should be done is: (a) transferring technology based on local potential, (b) facilitation of the government in the provision of bailouts and processing machines, and (c) support in the regulations in favor of the farmers.

Keywords: Empowerment, people's cocoa, independent society, transfer of technology industry, integration

PENDAHULUAN

Kakao merupakan salah satu komoditas ekspor yang mampu memberikan kontribusi peningkatan devisa Indonesia. Komoditas kakao menempati peringkat ke tiga ekspor sektor perkebunan dalam menyumbang devisa negara, setelah komoditas karet dan CPO. Indonesia merupakan pemasok ketiga terbesar di dunia setelah Pantai Gading dan Ghana dengan market share $13,6 \%$ dari total produksi dunia hingga tahun 2011,

Berdasarkan hal tersebut di atas, maka usaha pemerintah untuk meningkatkan daya saing kakao Indonesia di dunia internasional telah dilakukan dengan mencanangkan Gerakan Peningkatan Produksi dan Mutu Kakao Nasional (GERNAS). Agar gerakan GERNAS terlaksana, maka pembangunan wilayah perlu dilakukan secara komprehensif, terutama pada sentra-sentra komoditas unggulan, seperti komoditas kakao di Luwu Raya pada Provinsi Sulawesi Selatan. Wilayah ini merupakan produsen utama kakao Indonesia, diikuti Sulawesi Tengah, Sulawesi Tenggara, dan Sulawesi Barat. Dari ke empat propinsi tersebut, Sulawesi Selatan merupakan propinsi dengan pertumbuhan tertinggi yang mencapai $8,6 \%$. Khusus di Sulawesi Selatan sentra kakao terdapat di Luwu Raya, dengan Total produksi $63.259,21$ ton dari total Luas Areal 133.469,70 Ha yang terdiri dari 3 Kabupaten (Kabupaten: Luwu, Luwu Utara, dan Luwu Timur) dan 1 Kota yaitu Palopo Luwu Raya telah memberikan sumbangan 63 persen dari kakao nasional (sumber: Direktorat Jenderal Perkebunan, 2008).

Sayangnya, beberapa permasalahan masih menghadang pengembangan dalam industri kakao rakyat, yaitu: 1) utilisasi industri rendah $(<40 \%)$, 2) ekspor dalam bentuk biji kakao (70 \%), 3) Daya saing, 4) Standarisasi citarasa dan keamanan pangan, 5) Persaingan dengan produk impor dan 6) Diversikasi produk (Balai Penelitian Kopi dan Kakao Indonesia, 2011). Hal ini disebabkan oleh banyak 
faktor, dan salah satunya adalah masih adanya hambatan dalam alih teknologi yang berlangsung dari Balai-Balai Penelitian dan Perguruan Tinggi kepada petani kakao. Dalam proses alih teknologi, tidak dapat tergantung sepenuhnya terhadap gerak dinamika pengalih teknologi tersebut (Balai Penelitian maupun Perguruan Tinggi), tetapi dapat pula berasal dari dalam diri petani itu sendiri. Kemandirian petani dalam mengadopsi teknologi sangat dibutuhkan. Oleh karena itulah, untuk memberdayakan petani kakao agar mandiri, menjadi hal yang sangat penting agar mereka tidak tergantung kepada bantuan pemerintah. Itu perlu segera dilakukan, dan melibatkan berbagai pihak terutama pemerintah sebagai fasilitator. Hal ini mengingat program pemerintah di masa mendatang lebih mengarah ke industrialisasi kakao.

Berdasarkan peta panduan dari Bappenas (2011), di masa depan (20142025) sektor industri harus tumbuh secara nyata di atas pertumbuhan ekonomi, maka diperlukan alih industri yang dilakukan melalui percepatan pembangunan industri di daerah berlandaskan keunggulan komparatif dengan memfasilitasi percepatan pembangunan infrastruktur industri di daerah. Oleh karena itu, untuk menjabarkan Kebijakan Industri Nasional tersebut, proses alih industri dilakukan melalui pendekatan sektoral yang ditempuh melalui pengembangan klaster, industri unggulan provinsi, dan kompetensi inti industri daerah berlandaskan pada keunggulan komparatif yang dimiliki daerah; dikombinasikan dengan pendekatan regional melalui penyebaran konsentrasi industri ke daerah yang diarahkan menjadi pusat-pusat pertumbuhan industri. Saat ini, Direktorat Jenderal Pengembangan Perwilayahan Industri Kementerian Perindustrian (Kususnya Wilayah III) telah memusatkan perhatiannya untuk mengembangkan industri kakao di Wilayah Timur Indonesia (Sulawesi Selatan dan Sulawesi Tenggara).

Luwu Raya merupakan salah satu daerah sentra kakao di Provinsi Sulawesi Selatan dan masih cenderung menghasilkan biji kakao (bukan dalam bentuk olahan), oleh karena itu agar kakao rakyat lebih mandiri maka pemberdayaan harus diarahkan ke agroindustri, dan itu menjadi hal yang urgen. Untuk memberdayakan kakao rakyat menjadi masyarakat mandiri berbasis agroindustri kakao, harus 
didukung oleh komoditas kakao nya sendiri mulai dari on-farm sampai offfarm yang saling terkait satu sama lain, dan bersifat integrative (terpadu) dan berkelanjutan.

\section{METODE PENELITIAN}

Teknik penelitian yang digunakan dalam penelitian ini adalah dengan menggunakan pendekatan studi deskriptif survey. Tempat penelitian yang dipilih adalah Luwu Raya di Provinsi Sulawesi Selatan, yang merupakan daerah sentra kakao, dan daerah yang termasuk Luwu Raya adalah: Kabupaten Luwu, Kabupaten Luwu Utara, Kabupaten Luwu Timur, dan Kota Palopo. Teknik pengumpulan data dilakukan dengan cara: studi kepustakaan dan wawancara dengan pihak terkait, yaitu pejabat pada lembaga/instansi pemerintah, koperasi, pabrikan, asosiasi petani kakao yang dipilih secara purposive, dan kelompok tani. Penggalian data sekunder juga dilakukan untuk melengkapi data primer, yaitu dengan cara: mengumpulkan dan mempelajari data tertulis berupa dokumen-dokumen atau transkip, koran, jurnal, bulletin, dan membuka akses melalui internet mencari website yang terkait dengan penelitian ini. Data dan informasi yang diperoleh selanjutnya dianalisis secara deskriptif korelatif.

\section{HASIL DAN PEMBAHASAN}

\section{Potensi Kakao Rakyat di Daerah Penelitian}

Pada umumnya biji kakao yang dihasilkan di Luwu Raya (kecuali Kabupaten Luwu Timur dan Kota Palopo) masih ada yang belum difermentasi. Kondisi ini akan mempengaruhi kualitas dan nilai jual dari produk yang bersangkutan. Dari hasil penelitian dapat diketahui, alasan petani tidak melakukan fermentasi karena alasan biaya yang harus dikeluarkan, selain itu merekapun menyatakan bahwa dengan tidak melakukan fermentasipun kakao mereka terjual walaupun dengan harga rendah. Keinginan cepat memperoleh uang dari hasil panen kakao mereka karena adanya dorongan tambahan kebutuhan untuk memenuhi kehidupan mereka sehari-hari.

Kabupaten Luwu Timur, menghasilkan biji yang sudah difermentasi dan pada umumnya diolah menjadi produk antara, dan sebagian kecil berupa end-product. Kabupaten ini dapat menjadi gerbang keluarnya produk akhir dari kakao, hal ini disebabkan karena Kabupaten Luwu Timur memiliki bandara perintis (Bandara Sorowako) dan 
pelabuhan internasional (Pelabuhan

Sorowako), sehingga memudahkan arus barang untuk masuk ke wilayah disekitarnya; dengan kata lain keberadaan pelabuhan internasional dan bandara di Kabupaten Luwu Timur sangat mendukung keluar-masuknya barang (perdagangan). Sedangkan, Kota Palopo merupakan pusat arus perdagangan kakao, hal ini berdasarkan perkembangan sektor industri kakao dari Tahun 2003 sampai Tahun 2008 yaitu 212 unit naik menjadi 294 unit usaha (Dinas Koperindag Kota Palopo, 2010). Pengembangan industri kakao untuk skala IKM sebenarnya mulai dirintis pada Tahun 2007 di Kota Palopo, dengan melibatkan seluruh pemangku kepentingan.

Potensi kakao rakyat di Luwu Raya dalam penyediaan bahan baku untuk industri kakao dapat dilihat dari luas lahan yang diusahakan untuk tanaman kakao, produksi, dan produktivitasnya. Bila dilihat dari produksi dan produktivitasnya, maka Kota Palopo paling tinggi dibandingkan dengan (diurutkan yang tinggi sampai terendah) Kabupaten: Luwu, Luwu Timur, dan Luwu Utara.

Tabel 1. Luas Lahan, Produksi dan Produktivitas Kakao Rakyat di Luwu Raya Provinsi Sulawesi Selatan

\begin{tabular}{|c|c|c|c|}
\hline Kabupaten & Luas lahan (ha) & Produksi (ton/tahun) & Produktivitas (ton/ha) \\
\hline Luwu (Belopa) & $24.231,00$ & $18.649,00$ & $\begin{array}{r}0,77 \\
(106,94 \% \text { dari rata-rata produktivitas } \\
\text { perkebunan besar) }\end{array}$ \\
\hline Luwu Utara & $56.188,00$ & $13.034,00$ & $\begin{array}{r}0,23 \\
(31,94 \% \text { dari rata-rata produktivitas } \\
\text { perkebunan besar })\end{array}$ \\
\hline Luwu Timur & $37.315,05$ & $16.938,86$ & $\begin{array}{r}0,45 \\
(62,50 \% \text { dari rata-rata produktivitas } \\
\text { perkebunan besar })\end{array}$ \\
\hline Kota Palopo & $101.970,00$ & $81.600,00$ & $\begin{array}{r}0,80 \\
(111,14 \% \text { dari rata-rata produktivitas } \\
\text { perkebunan besar) }\end{array}$ \\
\hline
\end{tabular}

Sumber: Bappeda Kabupaten Luwu Timur. 2011

Keterangan: Produktivitas Kakao untuk Perkebunan Besar adalah: 0,72 ton/ha

Selanjutnya, untuk mendukung keberlanjutan agroindustri berbasis kakao di Luwu Raya, tidak cukup hanya didukung oleh luas lahan, produksi dan produktivitas tanaman kakaonya, tetapi juga harus didukung oleh fasilitas yang dimiliki oleh setiap daerah yang bersangkutan dan kemampuan industri daerah (baik dalam penyediaan mesin dan peralatan maupun listrik serta air, maupun peraturan daerah/menteri untuk kompetensi komoditas lokal). Kondisi 
kompetensi daerah untuk mendukung wilayah penelitian dapat dilhat dalam agroindustri berbasis kakao di keempat Tabel 2.

Tabel 2. Kemampuan Daerah dalam Agroindustri Berbasis Kakao

\begin{tabular}{|c|c|c|}
\hline Kabupaten & Fasilitas yang dimiliki & Kemampuan industri daerah \\
\hline $\begin{array}{l}\text { Luwu } \\
\text { (Belopa) }\end{array}$ & $\begin{array}{l}\text { Mesin proses pengolahan coklat untuk } \\
\text { menghasilkan end-product }\end{array}$ & Masih dalam proses instalasi \\
\hline $\begin{array}{l}\text { Luwu } \\
\text { Utara }\end{array}$ & $\begin{array}{l}\text { Sudah ada mesin proses pengolahan coklat } \\
\text { untuk menghasilkan end-product, dan dapat } \\
\text { berjalan dengan baik (dikelola oleh KUB } \\
\text { Resoe Sibali) }\end{array}$ & $\begin{array}{l}\text { Hasil produksinya sudah dipasarkan } \\
\text { di wilayah Luwu Utara. Perlu } \\
\text { mengembangkan inovasi end-product }\end{array}$ \\
\hline $\begin{array}{l}\text { Luwu } \\
\text { Timur }\end{array}$ & Mesin pengolah coklat skala laboratorium & $\begin{array}{l}\text { Pada umumnya diolah menjadi } \\
\text { produk lemak kakao, coklat bubuk } \\
\text { dengan merk "Sayang dan Sehati". } \\
\text { Perlu mengembangkan inovasi end- } \\
\text { product }\end{array}$ \\
\hline $\begin{array}{l}\text { Kota } \\
\text { Palopo }\end{array}$ & $\begin{array}{l}\text { Mesin pengolah coklat skala IKM, } \\
\text { berkemampuan menghasilkan end-product, } \\
\text { seperti: tree in one, bubuk coklat murni, } \\
\text { lemak kakao yang diolah menjadi kosmetik, } \\
\text { permen dan minuman coklat. Kualitas } \\
\text { produk yang dihasilkan baik, terlihat dari } \\
\text { banyaknya pesanan dan komentar dari } \\
\text { konsumen bahwa rasa coklat produk } \\
\text { Palopo setara dengan produk coklat buatan } \\
\text { luar negeri }\end{array}$ & $\begin{array}{l}\text { Sudah mampu mengolah berbagai } \\
\text { macam produk kakao olahan, dan } \\
\text { pemasaran produknya tidak saja local } \\
\text { tetapi sudah keluar daerah Kota } \\
\text { Palopo (Kabupaten dan provinsi } \\
\text { luar) }\end{array}$ \\
\hline
\end{tabular}

Berdasarkan Tabel 2, maka kompetensi untuk menghasilkan endproduct yang memiliki variasi cukup banyak terdapat di Kota Palopo, sayangnya Permen Kompetensi Inti Industri Daerah diperuntukan bagi rumput laut. Padahal keberadaan Permen akan sangat diperlukan untuk keberlangsungan dan keberlanjutan agroindustri berbasis kakao di daerah ini.

Untuk mengembangkan agroindustri berbasis kakao, perlu meningkatkan kemampuan petani kakao di wilayah Luwu Raya. Kemampuan mereka dalam menyediakan biji kakao yang difermentasi sebagai bahan baku agroindustri kakao, dapat dilihat dari usaha mereka dalam melakukan fermentasi (Tabel 3). Pada umumnya, petani di wilayah Luwu Raya belum melakukan fermentasi terhadap biji kakaonya, hal tersebut diakibatkan karena: a) petani membutuhkan uang dalam waktu cepat karena terdesak dengan kebutuhan hidup, b) belum adanya wadah kelompok tani (koperasi yang mandiri) yang dapat mengayomi (dalam arti membeli secara cash hasil panen petani dalam bentuk nonfermentasi), dan c) masih minimnya 
peralatan untuk fermentasi yang dimiliki

kelompok tani.

Tabel 3. Bentuk Produk dan Usaha Peningkatan Nilai Tambah Produk Kakao

\begin{tabular}{lll}
\hline Kabupaten & Bentuk Produk & Usaha Peningkatan Nilai Tambah Produk kakao \\
\hline $\begin{array}{l}\text { (Buwu } \\
\text { Belopa) }\end{array}$ & $\begin{array}{l}\text { Biji banyak yang belum } \\
\text { difermentasi (rata-rata hanya } \\
\text { dijemur 1 hari) }\end{array}$ & $\begin{array}{l}\text { Belum ada usaha untuk mengolah biji kakao menjadi } \\
\text { produk antara apalagi produk jadi (end-product) }\end{array}$ \\
\hline $\begin{array}{l}\text { Luwu } \\
\text { Utara }\end{array}$ & $\begin{array}{l}\text { Masih ada petani yang belum } \\
\text { melakukan fermentasi dengan } \\
\text { alasan perlu biaya tambahan, } \\
\text { tetapi adapula yang } \\
\text { menghasilkan end-product } \\
\text { (H.Rusdy) }\end{array}$ & $\begin{array}{l}\text { Ada satu unit industri yang menghasilkan } \text { end- } \\
\text { product (H.Rusdy), walaupun hasil } \text { end-product nya } \\
\text { masih berkualitas kurang baik. Produk yang } \\
\text { dihasilkan berukuran kecil dan besar (berbentuk } \\
\text { lempengan). }\end{array}$ \\
& $\begin{array}{l}\text { Biji sudah difermentasi dan } \\
\text { pada umumnya diolah menjadi } \\
\text { produk antara, dan sebagian } \\
\text { kecil berupa } \text { end-product }\end{array}$ & $\begin{array}{l}\text { Pada umumnya diolah menjadi produk antara, dan } \\
\text { sebagian kecil berupa } \text { end-product, dan sudah } \\
\text { memiliki kualitas yang cukup baik daripada produk } \\
\text { yang dihasilkan di Luwu Utara (H. Rusdy). Bentuk } \\
\text { produk yang dihasilkan adalah bubuk dan permen. }\end{array}$ \\
\hline $\begin{array}{l}\text { Kota } \\
\text { Palopo }\end{array}$ & $\begin{array}{l}\text { Biji banyak yang belum } \\
\text { difermentasi (rata-rata hanya } \\
\text { dijemur 1 hari) }\end{array}$ & $\begin{array}{l}\text { Sudah ada satu unit rumah coklat (tetapi belum } \\
\text { lounching), produk yang dihasilkan memiliki variasi } \\
\text { yang cukup banyak, seperti: tree in one, bubuk coklat } \\
\text { murni, lemak kakao yang diolah menjadi kosmetik, }\end{array}$ \\
& & permen dan minuman coklat. \\
\hline
\end{tabular}

Selanjutnya, dari hasil penelitian yang telah dilakukan (pada tahun 20112012) bersama-sama dengan Ditjen PPI Kementrian Perindustrian dan juga Balai Kopi dan Kakao Indonesia (2011) dapat diidentifikasikan bahwa, wilayah Luwu Raya dibagi ke dalam tiga macam golongan industri, yaitu: industri hulu, industri antara dan industri hilir. Maksud pengelompokan tersebut adalah, untuk percepatan dan pemerataan pembangunan industri kakao di Luwu Raya. Berdasarkan pengelompokan tersebut, alih informasi secara sistem dapat lebih mudah dilakukan. Pengelompokan wilayah Luwu Raya berdasarkan golongan industri, adalah:
1) Kabupaten Luwu masuk ke dalam kriteria industri hulu

2) Kabupaten Luwu Utara masuk ke dalam kriteria industri antara

3) Kabupaten Luwu Timur masuk ke dalam kriteria industri hulu

4) Kota Palopo Pusat masuk ke dalam kriteria industri hilir

Keempat wilayah tersebut, akan berjalan bila pembinaan terhadap petani yang ada di wilayah tersebut dilakukan secara sistem, melalui koordinasi wilayah satu dengan yang lainnya, dengan didukung oleh perguruan tinggi, balai penelitian dan pemerintah pusat dan daerah. 


\section{Alih Teknologi Industri Dalam Upaya Pemberdayaan Petani Kakao}

Alih teknologi adalah perpindahan suatu teknologi yang dihasilkan dan atau yang digunakan di suatu tempat untuk diaplikasikan ke tempat lain sebagai suatu teknologi inovasi (UNIDO, 1996). Agar alih teknologi dapat berjalan dengan baik dengan kata lain, dapat diterima oleh sasaran, dalam contoh kasus ini adalah petani kakao rakyat di Luwu Raya maka, petani kakao di wilayah Luwu Raya harus saling berinteraksi dan terintegrasi berdasarkan potensi yang dimiliki oleh masing-masing kabupaten/kota di wilayah tersebut. Potensi yang dimaksud tidak saja dari sisi manusianya (kemandirian), tetapi juga dari sisi: dukungan kebijakan, keberadaan stakeholder yang menunjang, sistem informasi teknologi industri pengolahan kakao, dan fasilitas penunjang lainnya (sarana dan prasarana jalan, komunikasi, peralatan/ mesin pengolahan). Selain itu, harus bersifat sistem saling terkait satu sama lain. Sistem yang dimakssud di sini adalah adanya sifat saling memberi dan menerima teknologi yang sudah dimiliki oleh masing-masing daerah berdasarkan kompetensi masing-masing secara mandiri, sekaligus mengadopsi teknologi yang terus diberikan oleh balai penelitian dan perguruan tinggi.
Koordinasi dan integrasi diperlukan untuk memperkuat sistem tersebut di atas dan mempermudah jalinan, yaitu antara petani kakao yang ada disatu wilayah dengan petani kakao di wilayah lain. Oleh karena itu, maka alangkah baiknya bila dalam melakukan pemberdayaan kelompok tani kakao yang ada di Luwu Raya digabung ke dalam kelompok UKM Industri Kakao, untuk lebih memudahkan dalam mengakses segala fasilitas yang disediakan oleh pemerintah, dan juga dalam menerima alih teknologi atau mencari informasi seluas-luasnya dari para stakeholdernya. Agar alih informasi dapat berjalan dengan cepat dan lancar, maka penentuan orang (anggota sistem sosial) yang tepat dan dipercaya dapat menjalankan alih teknologi dengan baik kepada anggota sistem sosial lainnya, harus benar-benar merupakan orang pilihan. Oleh karena itulah, untuk mempercepat proses alih teknologi dalam kabupaten/kota maupun keluar kabupaten/kota, dibutuhkan tipe petani yang memiliki karakter pelopor dan penerap dini. Tipe inilah yang harus ada dalam kelompok UKM Industri Kakao, dan lebih memungkinkan untuk dipilih atau diseleksi dalam kegiatan alih teknologi di tingkat kabupaten/kota. Melalui kelompok UKM Industri Kakao 
inilah maka alih teknologi dari perguruan tinggi dan balai penelitian yang ada, akan membuat kelompok UKM industri kakao yang inovatif, memiliki "bargaining power" yang tinggi dalam melakukan kemitraan dengan perusahaan-perusahaan yang lebih besar.

Agar dinamika fungsionalisasi lembaga riset, perguruan tinggi dan pemerintah dapat berjalan dengan baik, maka model pembinaan yang dapat diterapkan dapat melalui beberapa model, yaitu:

1) Model Mentoring: membimbing secara intensif (industri yang sudah jalan)

2) Model Inkubasi: mendewasakan usaha pemula sampai bisa jalan (IKM kakao)

3) Model Klaster: menjalin kemitraan dengan industri UKM dan industri besar

4) Model Mediasi: membuka akses pasar

Keempat model tersebut di atas dapat dilakukan secara berurutan, dimulai dari model (1) berlanjut sampai model (4). Kota Palopo yang merupakan basis industri hilir, dapat digunakan sebagai wadah inkubator bagi wilayah lainnya yang ingin meningkatkan produksi (kuantitas dan kualitas produk); demikian pula bagi Kabupaten Luwu Utara yang merupakan wilayah berbasis industri antara, dapat menjadi wadah bagi pengembangan wilayah yang berbasis industri hulu (Kabupaten Luwu dan Kabupaten Luwu Timur).

Karakteristik industri yang berbeda di keempat wilayah yang ada di Luwu Raya tersebut, akan menyebabkan pembinaan yang akan dilakukan pemerintah (instansi terkait) akan mengacu kepaga konsep "saling menerima dan memberi dalam alih teknologi”. Kakao rakyat yang memiliki industri tingkat teknologi lebih tinggi dapat dijadikan tempat magang bagi industri kakao rakyat yang masih tertinggal tingkat teknologinya. Selanjutnya, Perguruan Tinggi dan BalaiBalai Penelitian dapat membantu yaitu, berlaku sebagai tutor dan pemerintah pusat (Ditjen Pengembangan Perwilayahan Industri Kementrian Perindustrian) dan pemerintah daerah berfungsi sebagai fasilitator.

\section{Pemberdayaan UKM Sebagai Masyarakat Mandiri}

Kesiapan petani kakao menghadapi era globalisasi adalah menyangkut kualitas perilaku petani, terutama sekali dalam mengadopsi alih teknologi dari lembaga-lembaga terkait (lembaga 
penelitian maupun perguruan tinggi). Kesiapan petani akan menentukan kemampuan petani untuk mampu mandiri. Soemardjo (1999) menyatakan bahwa, terdapat faktor eksternal dan internal yang dapat mempengaruhi kemandirian petani; dan faktor eksternal petani menunjukkan peranan yang nyata bahkan lebih menarik dibandingkan dengan faktor internal petani dalam perkembangan kemandirian petani. Berdasarkan penelitian Soemardjo (1999) tersebut, terdapat beberapa hal yang mempengaruhi kemandirian petani, salah satunya adalah: keterjangkauan petani terhadap sarana penunjang pertanian menunjukkan pengaruh yang paling peka, positif, dan nyata terhadap perilaku modern serta efisien petani. Selain itu, masih terdapat hal lain yang turut mempengaruhi, yaitu: a) aksesibilitas petani terhadap pasar produk pertanian, b) perilaku modern petani, c) perilaku efisiensi petani, d) keterjangkauan petani atas sarana penunjang usahatani, e) persepsi petani terhadap kelayakan fisik usahatani, f) aksesibilitas petani terhadap sumberdaya informasi, g) desakan perkembangan sektor non-pertanian, h) kualitas penyuluhan, i) penetrasi produk lain kedalam kebutuhan rumah tangga petani, dan j) persepsi petani terhadap kebijakan pembangunan pertanian.

Berdasarkan uraian tersebut di atas, maka untuk mengembangkan petani agar dapat menjadi manusia yang mandiri maka diperlukan kerjasama yang terpadu, menyeluruh dan berkesinambungan antara masyarakat, pemerintah, perguruan tinggi, serta stakeholder lainnya untuk bersama-sama melakukan perubahan mentalitas pembangunan berdasarkan nilai-nilai budaya tersebut di atas.

Disamping keempat butir di atas, Koentjaraningrat (1983) juga menyatakan bahwa, agar pembangunan berhasil maka masyarakat Indonesia harus memiliki mentalitas percaya akan kemampuan diri sendiri, berdisiplin, dan bertanggung jawab atas apa yang ia lakukan. Masyarakat Indonesia yang memiliki mentalitas seperti tersebut di atas, pada akhirnya akan dapat mandiri dan bergerak penuh dalam pembangunan nasional.

UKM mampu tumbuh lebih cepat dari usaha besar bila diberi peluang. Di Jepang, Jerman, Swedia, dan Italia usaha kecil elektronika, mampu melakukan penemuan, inovasi, dan bisa efisiensi. Schmitz percaya bahwa usaha kecil dan menengah akan mendominasi dan mendorong perkembangan ekonomi suatu 
bangsa, dengan syarat mereka mampu meningkatkan efisiensi dan daya saingnya.

Pertanyaanya adalah apa yang harus dilakukan pemerintah? Pemerintah perlu membuat kebijakan kelembagaan untuk memberikan iklim yang kondusif bagi beroperasinya UKM. Untuk itu maka ada beberapa prinsip yang harus diperhatikan (Aliwear, 2012). Prawirokusumo (1999) dalam Aliwear (2012) mengemukakan beberapa hal yang harus mendapat perhatian dalam pemberdayaan UKM: (a) kebijakan persaingan sehat dengan pengurangan distorsi pasar, (b) kebijakan ekonomi yang memberi peluang UKM dapat mengurangi beban biaya yang tidak berhubungan dengar proses produksi, dan (c) kebijakan penumbuhan kemitraan dengan prinsip saling memerlukan, memperkuat, dan saling menguntungkan. Selanjutnya dukungan penguatan yang meliputi: peningkatan kualitas SDM koperasi dan UKM; peningkatan penguasaan teknologi; peningkatan penguasaai informasi; peningkatan penguasaan permodalan; peningkatan penguasaan pasar, pengoptimalan organisasi dan manajemen; pencadangan tempat usaha ; dan pencadangan bidangbidang usaha. Untuk membuat petani kakao bisa kokoh mandiri dalam mengembangkan agroindustri berbasis kakao, maka alih teknologi harus memenuhi kriteria ketepatgunaan (appropriate technology) seperti: 1) segi teknis dapat dilaksanakan; 2) segi sosial akseptabel; 3) secara ekonomi dapat dipertanggungjawabkan; dan 4) secara ekologi tidak menurunkan kualitas hidup.

\section{KESIMPULAN DAN SARAN}

Pemberdayaan kakao rakyat menjadi masyarakat mandiri melalui agroindustri berbasis kakao rakyat di Luwu Raya Provinsi Sulawesi Selatan, Berdasarkan hasil penelitian, pemberdayaan kakao rakyat menjadi masyarakat mandiri melalui agroindustri menjadi suatu keniscayaan, mengingat potensi kakao rakyat dalam menghasilkan biji kakao cukup besar dan hanya sebagian kecil yang diolah menjadi produk jadi. Agar menjadi masyarakat mandiri maka yang harus dilakukan adalah: (a) melakukan alih teknologi berdasarkan potensi lokal, (b) fasilitasi pemerintah dalam penyediaan dana talangan dan mesin pengolah, dan (c) dukungan dalam regulasi yang berpihak kepada petani.

Selanjutnya, agar agroindustri berbasis kakao rakyat dapat menciptakan 
kemandirian dan berkelanjutan, maka harus: (a) materi informasi teknologi harus disesuaikan dengan kebutuhan petani, (b) materi informasi teknologi harus mudah dan murah sehingga dapat terjangkau oleh permodalan yang dimiliki petani, (c) materi informasi teknologi harus disesuaikan dengan kondisi sosial dan budaya setempat, (d) menciptakan koordinasi, integrasi, sinkronisasi dan simplifikasi antar pelaku industri kakao (stakeholder), (e) menciptakan kerjasama yang sinergi, (f) adanya dukungan regulasi dari pemerintah yang berpihak kepada petani, (g) adanya dana talangan untuk membeli biji kakao yang tidak difragmentasi, dan (h) adanya bantuan mesin fermentasi dan pengolahan yang bersifat spesifik lokal.

\section{UCAPAN TERIMAKASIH}

Akhir kata kami mengucapkan terima kasih kepada:

1. Ditjen PPI Kementrian Perindustrian RI atas kepercayaannya dalam penyusunan Master Plan Pusat Inovasi Industri Berbasis Kakao, di Luwu Raya, Sulawesi Selatan.

2. BPIHP Sulawesi Selatan atas kerjasama yang baik dan dukungannya selama melakukan survey lapangan dan laporan akhir.
3. Kepala Dinas dan Staff di Kabupaten terkait: Luwu Timur, Luwu Utara, Luwu dan Kota Polopo.

4. Semua pihak atas peran serta dan dukungannya dalam penelitian ini.

\section{DAFTAR PUSTAKA}

Aliwear. 2012. (https://alisadikinwear. wordpress.com/ 2012/05/17/peranpemerintah-daerah-dalampemberdayaan-ukm/).

Bappeda Kabupaten Luwu Timur. 2011. Rencana Pembangunan Jangka Menengah Kabupaten Luwu Timur.

Dinas Koperindag Kota Palopo. 2010. Rencana Pengembangan Industri Pengolahan Kakao Kota Palopo.

Ditjen PPI Kementerian Perindustrian. 2011. Penyusunan Master Plan Pusat Inovasi Industri Berbasis Kakao di Luwu Propinsi Sulawesi Selatan.

Koentjaraningrat.1983. Kebudayaan, Mentalitas dan Pembangunan. Jakarta: PT. Gramedia.

Sumardjo. 1999. Alih Model Penyuluhan Pertanian Dimensi Partisipatif Penyuluh dan Petani. Disertasi. Program Pasca Sarjana IPB; Bogor. United National Iidustrial Development Organization (UNIDO). 1996. The Role of Transfer of Technology in The Development Process. Manual on Technology Transfer Negotiations.

Pattiasina dan Alfah. 2012. Analisis Pendapatan Usahatani Kakao (Theobroma cacao L) di Desa Latu. Jurnal Budidaya Pertanian, Vol.8 No.1 Juli 201.

Poedjiwidodo. 1996. Sambung Samping Kakao. Yogyakarta: Trubus Agriwidya.

Pusat penelitian kopi dan Kakao Indonesia 2004. Panduan Lengkap 
Budidaya Kakao. Agromedia Pustaka.

Sugyono. 213. Metode Penelitian Kuantitatif dan Kualitatif. Bandung: Alfabeta.
Sustainable Cocoa Production program (SCCP). 2012. Penerapan Budidaya terbaik Tanaman Kakao. USDA. 2012. Good Agricutural Practices Good Handling Practices Audit Verification Checklist. 